\title{
Multicenter research into the quality of life of patients with advanced oropharyngeal carcinoma with long-term survival associated with human papilloma virus
}

\author{
GIACOMO SPINATO $^{1 *}$, MARCO STELLIN $^{2 *}$, GIUSEPPE AZZARELLO $^{3 *}$, \\ DEBORAH BONAZZA ${ }^{4 *}$, FABRIZIO ZANCONATI $^{4 *}$, DORIANO POLITI $^{5 *}$, SALVATORE COCUZZA $^{6 *}$, \\ PAOLA DI MAURO $^{6 *}$, SIMONETTA AUSONI ${ }^{7 *}$, GIOVANNI TONOLI ${ }^{1 *}$, GIULIO COSTANTINI ${ }^{8^{*}}$, \\ LUIGI MAIOLINO $^{6 *}$, ROBERTO SPINATO ${ }^{* *}$, MARIA CRISTINA DA MOSTO ${ }^{2 *}$, LORENA BABOCI ${ }^{9^{*}}$, \\ ANNAROSA DEL MISTRO ${ }^{9 *}$, AGOSTINO SERRA $^{6^{*}}$ and GIANCARLO TIRELLI ${ }^{10^{*}}$ \\ ${ }^{1}$ Ear, Nose and Throat Department, Rovigo Provincial Hospital, I-45100 Rovigo; \\ ${ }^{2}$ Department of Neurosciences, Ear, Nose and Throat Clinic and Regional Center for Head and Neck Cancer, \\ University of Padua, Treviso Provincial Hospital, I-35122 Padua; ${ }^{3}$ Medical Oncology Department, \\ Mirano Hospital, I-300035 Venice; ${ }^{4}$ Pathology Department, Cattinara Hospital, University of Trieste, \\ I-34149 Trieste; ${ }^{5}$ Provincial Ear, Nose and Throat Department of Venice, Mestre Hospital, I-30174 Venice; \\ ${ }^{6}$ Ear, Nose and Throat Department, University of Catania, I-95125 Catania; ${ }^{7}$ Department of Biomedical Sciences, \\ University of Padua, I-35122 Padua; ${ }^{8}$ Psychology Department, University of Milano-Bicocca, I-20126 Milan; \\ ${ }^{9}$ Veneto Institute of Oncology IOV-IRCCS, Immunology and Molecular Oncology Unit, Padua, I-35128 Padova; \\ ${ }^{10}$ Ear, Nose and Throat Department, Cattinara Hospital, University of Trieste, I-34149 Trieste, Italy
}

Received August 11,2016; Accepted November 28, 2016

DOI: $10.3892 / \mathrm{ol} .2017 .6152$

\begin{abstract}
The treatment of advanced-stage oropharyngeal squamous cell carcinoma may utilize various modes, including combining surgery with chemoradiotherapy (CTRT), or primary CTRT followed by rescue surgery. In previous literature it has been revealed how patients treated with combined modes report a low quality of life $(\mathrm{QoL})$ and severe consequences following surgery, radiotherapy and chemotherapy, in the short and in the long-term. The decrease in the QoL of patients treated with high-intensity multi-modal strategies highlights the necessity of modifying treatments, particularly for young HPV-positive patients, where an increased survival rate has already been reported. The modified treatment for HPV-positive tumors in the tonsils and at the base of the tongue is based on the deintensification of therapies aiming to reduce toxicity and thereby improve QoL in the long term, whilst still maintaining therapeutic effectiveness. The aim of
\end{abstract}

Correspondence to: Professor Salvatore Cocuzza, Ear, Nose and Throat Department, University of Catania, Via Santa Sofia 78, I-95125 Catania, Italy

E-mail: s.cocuzza@unict.it

${ }^{*}$ Contributed equally

Key words: oropharyngeal carcinoma, quality of life, human papillomavirus, radiochemotherapy, deintensification therapy the present study was to evaluate the QoL in patients with a long-term survival, who were treated with combined therapy for squamous cell tumors in the tonsils and at the base of the tongue, and to compare the results observed in HPV-positive and HPV-negative patients. According to statistical analysis, differences in the general QoL and in the single scales of the European Organization for the Research and Treatment of Cancer questionnaires were not correlated with the type of therapy selected for the particular patient. QoL considered the presence of HPV, the type of treatment, the subregion of the tonsils vs. the base of the tongue and the disease stage at the time of diagnosis, and was determined to be non-influential with regard to these specific variables.

\section{Introduction}

Squamous cell oropharyngeal carcinoma is a disease with a rising incidence in various Western countries (1). This increase is primarily due to a high number of human papillomavirus (HPV)-associated tumors in the tonsils and at the base of the tongue $(1,2)$. It has been established that HPV squamous cell cancer has an improved diagnosis and clinical outcomes, as compared with HPV-negative tumors (1-3).

Squamous cell cancer in the tonsils and at the base of the tongue is often diagnosed in an advanced loco-regional phase, which is stage III-IVB (1). Squamous cell carcinoma treatments at these stages may use various modes, including combining surgery with chemoradiotherapy (CTRT) or primary CTRT followed by rescue surgery (4). A review of the literature revealed that patients treated with combined modes typically 
reported a low quality of life (QoL), with severe consequences following surgery, radiotherapy and chemotherapy, in the short and in the long-term $(5,6)$. The decrease in the QoL of patients treated with high-intensity multi-modal strategies highlights the necessity of modifying treatments, particularly for young HPV-positive patients, where an increased survival rate has already been reported. $(1,3,7,8)$. The modified treatment for HPV-positive tumors in the tonsils and at the base of the tongue is based on the deintensification of current therapies, with the aim of reducing toxicity and, therefore, improving long-term QoL, whilst also maintaining therapeutic effectiveness $(3,9)$.

To date, few studies have analyzed the QoL for long-term survival patients who were treated with combined therapy for oropharyngeal squamous cell cancer in the tonsils or at the base of the tongue (10). The incidence of oropharyngeal squamous cell cancer is increasing in Western countries, by contrast with a decrease in the incidence of other types of carcinoma in alternate cervicofacial regions, despite a reduced smoking prevalence (1). Infection with HPV, particularly HPV type 16 , is currently considered to be an important factor for the insurgency of HPV-positive oropharyngeal carcinomas, which exhibit various radiological, epidemiological, clinical, anatomical, biological and prognostic features, when compared with HPV-negative carcinomas $(3,11)$. The only region in the cervicofacial area with a demonstrated viral etiological connection is the oropharynx $(3,8)$. These studies raise certain questions about the choice of therapy and the intensity of treatment that should be used depending on the stage of the HPV tumor $(12,13)$.

The aim of the present study was to evaluate the QoL of patients with a long-term survival, who were treated with combined therapy for squamous cell tumors in the tonsils and at the base of the tongue, and then to compare the QoL results reported by patients who were HPV-positive and HPV-negative. As HPV is associated with an improved response to treatment and a greater survival time, it was hypothesized that patients with HPV-high-risk (HR)-associated oropharyngeal squamous cell carcinoma may have an improved QoL. Understanding the association between the HPV status and the post-treatment QoL may improve the management of patients with squamous cell HPV-HR-associated carcinoma and potentially enable the development of personalized therapy, in order to optimize not only the survival rate, but also the QoL for each patient.

\section{Materials and methods}

Patients. The present study involved multicenter research, as the patients were recruited and attended follow-ups at either the Ear, Nose and Throat (ENT) Department of the University of Trieste (Trieste, Italy), the ENT Unit of Treviso Hospital (Treviso, Italy), University of Padua (Padua, Italy), the Interhospital ENT Department of the Province of Venice (Venice, Italy) or the ENT Department of the University of Catania (Catania, Italy).

The present cross-sectional study used the following inclusion criteria: The presence of a squamous cell tumor in the tonsils or at the base of the tongue at stage III-IVB; patients who had not previously been treated for squamous cell tumors in the tonsils or at the base of the tongue, regardless of the correlation with HPV; treatment that includes surgery alone or plus CTRT, or primary CTRT \pm rescue surgery; complete remission following treatment; treatment was completed $\geq 60$ months prior to being included in the present study; patients who exhibited signs of remission following the completion of the questionnaire.

A total of 48 patients, 34 males (71\%) and 14 females (29\%), were recruited for the present study. The age ranged between 40-79 years old at the time of diagnosis. All the recruited patients signed an informed consent. Among the cases collected from the various recruitment centers, each had a survival time of $\geq 5$ years following treatment for oropharyngeal squamous cell carcinoma; those patients with stage I/II disease, with oropharyngeal carcinoma not associated with the tonsils or the base of the tongue, or who were not completely recovered from the disease were not included. The patient clinical features, tumor sub-region, tumor-node-metastasis (TMN) grade stage and HPV status are summarized in Table I. The number of recruited cases, considering the age at the time of diagnosis, is summarized in Table II.

Questionnaires. QoL was evaluated using questionnaires prepared by the European Organization for the Research and Treatment of Cancer (EORTC), in particular using the general questionnaire analyzing QoL: QoL Questionnaire-Core 30 (QLQ-C30) and the specific questionnaire for the head and neck area (35/QLQ-H\&N35) $(14,15)$. These questionnaires were completed during follow-up appointments or under specific doctor's request, in person or over the phone. The results of the QoL questionnaires were analyzed according to the specific scoring manual provided by the EORTC $(16,17)$, all scores were expressed on a scale ranging between 0-100.

Laboratory examination. For molecular analysis formalinfixed paraffin-embedded (FFPE) tumor samples were used. All tumor samples were tested for the presence of HPV and details of the method are already published in Baboci et al (18). Briefly, DNA was extracted and amplified through broad spectrum L1 multiplex human papillomavirus genotyping (BS-L1-MPG assay) (19). In total, $150 \mathrm{bp}$ for the gene L1 of $\sim 51$ types of mucosal HPV were amplified. Detection of the human $\beta$-globin gene was used as a control for the quality of DNA, as well as a control for polymerase chain reaction (PCR).

The DNA samples were also analyzed using MY09/11-PCR amplification, followed by Restriction Fragment Length Polymorphism and direct sequencing (20). Additionally, the expression of p16 protein was immunohistochemically analyzed from the same FFPE tumor samples. Due to limited sample availability, p16 protein expression was analyzed in 29 patients using CINtec ${ }^{\circledR}$ p $16^{\mathrm{INK} 4 \mathrm{a}}$ Histology, ready-to-use mouse monoclonal antibody (clone $\mathrm{E} 6 \mathrm{H} 4^{\mathrm{TM}}$; cat. no. 06695248001; Roche Diagnostics, Basel, Switzerland) on Automated immunohistochemistry stain Ventana BenchMark Ultra (Roche Diagnostics). Sections of tissue (2-4 $\mu \mathrm{m})$ were deparaffinized with Ez-Prep $1 \mathrm{X}$ for $25 \mathrm{~min}$ at $72^{\circ} \mathrm{C}$ (cat. no. 05279771001; Roche Diagnostics). Subsequently, on-board heat antigenic retrieval was performed for $36 \mathrm{~min}$ at $95^{\circ} \mathrm{C}$ in Ultra CC1 (Tris-Borate-EDTA pH 8.2; cat. no. 05424569001; Roche Diagnostics) $(21,22)$. Slides were left to cool on-board by the system for $4 \pm 1 \mathrm{~min}$. Endogenous peroxidase enzymes were blocked with $3 \%$ hydrogen peroxide for $4 \mathrm{~min}$ at $36^{\circ} \mathrm{C}$ 
Table I. Clinicopathological characteristics of patients with advanced oropharyngeal carcinoma.

\begin{tabular}{|c|c|c|c|c|c|c|c|c|c|}
\hline No. & Name & Gender & Age & Location & Year of diagnosis & Treatment & TNM & Stage & HPV \\
\hline 1 & A1 & M & 71 & $\begin{array}{l}\text { Bilateral tonsil-base } \\
\text { of the tongue soft palate }\end{array}$ & 2008 & $\mathrm{CTRT}+\mathrm{SG}$ & $\mathrm{T} 3 \mathrm{~N} 2 \mathrm{~b}$ & IV & $\mathrm{N}$ \\
\hline 2 & A2 & M & 66 & Tonsil-base of the tongue & 2008 & $\mathrm{CTRT}+\mathrm{SG}$ & $\mathrm{T} 2 \mathrm{~N} 2 \mathrm{~b}$ & IV & $\mathrm{P}$ \\
\hline 3 & A3 & M & 64 & Tonsil & 2005 & $\mathrm{CTRT}+\mathrm{SG}$ & $\mathrm{T} 2 \mathrm{~N} 1$ & III & $\mathrm{P}$ \\
\hline 4 & A4 & M & 56 & Tonsil & 2009 & $\mathrm{CTRT}+\mathrm{SG}$ & $\mathrm{T} 2 \mathrm{~N} 2 \mathrm{~b}$ & IV & $\mathrm{P}$ \\
\hline 5 & A5 & M & 56 & Tonsil-base of the tongue & 2007 & $\mathrm{CTRT}+\mathrm{SG}$ & $\mathrm{T} 4 \mathrm{aN} 2 \mathrm{~b}$ & IV & $\mathrm{N}$ \\
\hline 6 & A6 & $\mathrm{F}$ & 57 & $\begin{array}{l}\text { Tonsil-base of the tongue } \\
\text { Trigone-mandible }\end{array}$ & 2010 & $\mathrm{CTRT}+\mathrm{SG}$ & T3N2 & IV & $\mathrm{P}$ \\
\hline 7 & A7 & M & 60 & Tongue-oropharynx & 2004 & $\mathrm{CTRT}+\mathrm{SG}$ & $\mathrm{T} 4 \mathrm{aN} 2 \mathrm{~b}$ & IV & $\mathrm{P}$ \\
\hline 8 & A8 & M & 57 & Tonsil & 2008 & $\mathrm{SG}$ & T1N1 & III & $\mathrm{N}$ \\
\hline 9 & A9 & M & 52 & Base of the tongue-Trigone & 2010 & SG & T3N0 & III & $\mathrm{N}$ \\
\hline 10 & A10 & $\mathrm{F}$ & 56 & $\begin{array}{l}\text { Trigone-Tonsil-Bse } \\
\text { of the tongue }\end{array}$ & 2006 & CTRT+SG & T3N1 & III & $\mathrm{N}$ \\
\hline 11 & A11 & $\mathrm{F}$ & 73 & Tonsil & 2010 & $\mathrm{CTRT}+\mathrm{SG}$ & $\mathrm{T} 2 \mathrm{~N} 2 \mathrm{~b}$ & IV & $\mathrm{P}$ \\
\hline 12 & A12 & M & 68 & Tonsil-base of the tongue & 2007 & $\mathrm{CTRT}+\mathrm{SG}$ & $\mathrm{T} 3 \mathrm{~N} 2 \mathrm{c}$ & IV & $\mathrm{P}$ \\
\hline 13 & B1 & $\mathrm{F}$ & 65 & base of the tongue & 2006 & SG+RT & $\mathrm{T} 2 \mathrm{~N} 2$ & IV & $\mathrm{P}$ \\
\hline 14 & $\mathrm{~B} 2$ & M & 69 & Tonsil & 2003 & $\mathrm{SG}+\mathrm{RT}$ & $\mathrm{T} 2 \mathrm{~N} 2$ & IV & $\mathrm{N}$ \\
\hline 15 & B3 & M & 56 & Base of the tongue & 2006 & $\mathrm{SG}+\mathrm{RT}$ & T3N1 & III & $\mathrm{N}$ \\
\hline 16 & B4 & $\mathrm{F}$ & 46 & Base of the tongue+tongue & 2004 & $\mathrm{SG}$ & T2N1 & III & $\mathrm{P}$ \\
\hline 17 & B5 & M & 60 & Base of the tongue & 2006 & $\begin{array}{l}\text { SG on head } \\
\text { and neck and } \\
\text { lung+RT }\end{array}$ & T3N0 & III & $\mathrm{N}$ \\
\hline 18 & B6 & M & 58 & Base of the tongue & 2003 & CTRT & T4N2b & IV & $\mathrm{N}$ \\
\hline 19 & B7 & $\mathrm{F}$ & 62 & Base of the tongue & 2003 & SG & $\mathrm{T} 2 \mathrm{~N} 1$ & III & $\mathrm{N}$ \\
\hline 20 & B8 & M & 50 & Bilateral tonsil+velum & 2002 & $\mathrm{SG}+\mathrm{RT}$ & $\mathrm{T} 3 \mathrm{~N} 2 \mathrm{~b}$ & IV & $\mathrm{N}$ \\
\hline 21 & B9 & $\mathrm{F}$ & 58 & Tonsil & 2003 & $\mathrm{SG}+\mathrm{RT}$ & $\mathrm{T} 3 \mathrm{~N} 2$ & IV & $\mathrm{N}$ \\
\hline 22 & B10 & M & 53 & Base of the tongue & 2000 & $\mathrm{SG}+\mathrm{RT}$ & T3N2 & IV & $\mathrm{P}$ \\
\hline 23 & B11 & $\mathrm{F}$ & 65 & Tonsil & 2001 & $\mathrm{SG}$ & $\mathrm{T} 1 \mathrm{~N} 1$ & III & $\mathrm{N}$ \\
\hline 24 & B12 & $\mathrm{F}$ & 65 & Tonsil & 2000 & SG & T2N1 & III & $\mathrm{N}$ \\
\hline 25 & B13 & M & 52 & Tonsil-base of the tongue & 2000 & $\mathrm{SG}+\mathrm{RT}$ & T3N2 & IV & $\mathrm{P}$ \\
\hline 26 & B14 & M & 54 & Base of the tongue & 2000 & $\mathrm{SG}+\mathrm{RT}$ & T3N2 & IV & $\mathrm{P}$ \\
\hline 27 & B15 & M & 46 & Base of the tongue & 2001 & $\mathrm{SG}$ & T1N1 & III & $\mathrm{P}$ \\
\hline 28 & B16 & M & 58 & Base of the tongue & 2000 & SG & $\mathrm{T} 2 \mathrm{~N} 1$ & III & $\mathrm{N}$ \\
\hline 29 & B17 & M & 68 & Tonsil & 2002 & SG & $\mathrm{T} 2 \mathrm{~N} 1$ & III & $\mathrm{N}$ \\
\hline 30 & B18 & M & 71 & Tonsil & 2007 & RT & T3N2 & IV & $\mathrm{N}$ \\
\hline 31 & B19 & M & 75 & Tonsil & 2007 & $\mathrm{SG}+\mathrm{RT}$ & $\mathrm{T} 1 \mathrm{~N} 2 \mathrm{a}$ & IV & $\mathrm{N}$ \\
\hline 32 & B20 & $\mathrm{F}$ & 70 & Base of the tongue & 2007 & $\mathrm{SG}+\mathrm{RT}$ & $\mathrm{T} 1 \mathrm{~N} 2 \mathrm{a}$ & IV & $\mathrm{N}$ \\
\hline 33 & B21 & M & 58 & Base of the tongue & 2008 & SG & T1N1 & III & $\mathrm{P}$ \\
\hline 34 & B22 & M & 55 & Tonsil (+ 2005,2015) & 2008 & $\mathrm{SG}+\mathrm{RT}$ & T1N1 & III & $\mathrm{N}$ \\
\hline 35 & B23 & M & 55 & Base of the tongue & 2009 & $\mathrm{SG}+\mathrm{RT}$ & $\mathrm{T} 2 \mathrm{~N} 2 \mathrm{a}$ & IV & $\mathrm{P}$ \\
\hline 36 & B24 & M & 79 & Base of the tongue & 2010 & CTRT & $\mathrm{T} 2 \mathrm{~N} 2$ & IV & $\mathrm{N}$ \\
\hline 37 & $\mathrm{~B} 25$ & $\mathrm{~F}$ & 60 & Tonsil & 2008 & CTRT & $\mathrm{T} 2 \mathrm{~N} 1$ & III & $\mathrm{P}$ \\
\hline 38 & B26 & M & 58 & Tonsil & 2009 & CTRT & $\mathrm{T} 4 \mathrm{aN} 2 \mathrm{~b}$ & IV & $\mathrm{N}$ \\
\hline 39 & $\mathrm{~B} 27$ & M & 63 & Tonsil & 2009 & $\begin{array}{l}\text { CTRT+neck } \\
\text { dissection }\end{array}$ & T4N3 & IV & $\mathrm{N}$ \\
\hline 40 & B28 & M & 66 & Base of the tongue & 2010 & $\begin{array}{l}\text { CTRT+neck } \\
\text { dissection }\end{array}$ & $\mathrm{T} 3 \mathrm{~N} 2 \mathrm{~b}$ & IV & $\mathrm{N}$ \\
\hline 41 & B29 & $\mathrm{F}$ & 40 & Tonsil & 2008 & $\begin{array}{l}\text { CTRT+neck } \\
\text { dissection }\end{array}$ & $\mathrm{T} 1 \mathrm{~N} 2$ & IV & $\mathrm{P}$ \\
\hline 42 & $\mathrm{C} 1$ & $\mathrm{~F}$ & 68 & Left tonsil & 2009 & CTRT & T3N2c & IV & $\mathrm{P}$ \\
\hline 43 & $\mathrm{C} 2$ & M & 60 & Tonsil-right base of the tongue & 2009 & CTRT & T4N2b & IV & $\mathrm{P}$ \\
\hline 44 & $\mathrm{C} 3$ & M & 64 & Tonsil & 2004 & CTRT & T4N0 & IV & $\mathrm{N}$ \\
\hline 45 & $\mathrm{C} 4$ & M & 71 & Right tonsil & 2007 & CTRT & $\mathrm{T} 1 \mathrm{~N} 2 \mathrm{~b}$ & IV & $\mathrm{N}$ \\
\hline
\end{tabular}


Table I. Continued.

\begin{tabular}{|c|c|c|c|c|c|c|c|c|c|}
\hline N. & Name & Gender & Age & Location & Year of diagnosis & Treatment & TNM & Stage & HPV \\
\hline 46 & $\mathrm{C} 5$ & $\mathrm{M}$ & 49 & Base of the tongue & 1999 & $\mathrm{SG}+\mathrm{RT}$ & $\mathrm{T} 1 \mathrm{~N} 2 \mathrm{~b}$ & IV & $\mathrm{N}$ \\
\hline 47 & C6 & $\mathrm{M}$ & 54 & Base of the tongue & 2003 & CTRT & T4N1 & IV & $\mathrm{N}$ \\
\hline 48 & $\mathrm{C} 7$ & $\mathrm{~F}$ & 59 & Tonsil & 2000 & CTRT & T3N2a & IV & $\mathrm{N}$ \\
\hline
\end{tabular}

HPV, human papilloma virus; CTRT, chemotherapy-radiotherapy; TNM, tumor-node-metastasis; SG, surgery; P, positive; N, negative.

Table II. Analysis of the cohort of patients with advanced oropharyngeal carcinoma with regards to age.

\begin{tabular}{lc}
\hline Factor & Age, years old \\
\hline Average patient age & 69.74 \\
SD of age & 7.83 \\
Min age & 46.68 \\
Max age & 83.41 \\
Average age at the time of the diagnosis & 60.33 \\
SD of age at the time of the diagnosis & 8.11 \\
Min age at the time of the diagnosis & 40 \\
Max age at the time of the diagnosis & 79 \\
\hline
\end{tabular}

$\mathrm{SD}$, standard deviation.

(UltraView Universal DAB Inhibitor). The slides were incubated with the CINtec ${ }^{\circledast}$ p16 $6^{\text {INK4a }}$ Histology primary antibody for $24 \mathrm{~min}$ at $36^{\circ} \mathrm{C}$. Detection was then performed on-board with Ultraview DAB Detection kit (cat. no. 05269806001; Roche Diagnostics). UltraView DAB Detection kit Universal horseradish peroxidase-conjugated Multimer, $\alpha$-mouse/rabbit secondary antibody was added and incubated for $8 \mathrm{~min}$ at $36^{\circ} \mathrm{C}$. Subsequently, the signal was revealed with a chromogen-substrate solution (DAB plus $\mathrm{H} 2 \mathrm{O} 2$; Roche Diagnostics) for $8 \mathrm{~min}$ at $36^{\circ} \mathrm{C}$, followed by a signal enhancer step for $4 \mathrm{~min}$ at $36^{\circ} \mathrm{C}$ with copper sulfate. Final counterstain was performed using hematoxylin. Tissues positive for $\mathrm{p} 16$ were defined by clear and dispersed nuclear and cytoplasmic staining in $\geq 70 \%$ of tumor cells. Cervical HPV-positive tissue sections were used as positive controls and negative controls were produced by omitting the primary antibody (19).

Statistical analysis. Descriptive statistics were computed for all functioning and symptoms scale scores (Table III). A multivariate analysis of variance (MANOVA) approach was used to determine whether a number of interconnected and dependent variables, the scales of the QoL-C30 and those of the H\&N35, were influenced by the five following independent variables: i) HPV positivity (positive vs. negative); the 12 participants whose information was unavailable were excluded from the analysis that included HPV as a factor. ii) The type of treatment received by the patient (surgery vs. CTRT, vs. surgery and RT, vs. surgery and CTRT). It must be acknowledged that, concerning the analysis that included the type of treatment as an independent variable, no patients who were exclusively treated with RT without surgery were included. iii) The stage of the disease (III vs. IV); with regards to this predictor, no distinction was made between stage IVA and IVB, as only one patient was reported to have stage IVB disease. iv) The patient gender (male vs. female). v) The age of the patient at the time of diagnosis ( $<60$ vs. $\geq 60$ years).

In the prediction of the QLQ-C30 and H\&N35 scales, the five independent variables were included separately in each MANOVA, using the Wilks's $\lambda$ statistic test $(23,24)$. The approximate $\mathrm{F}$ distribution was used to evaluate the impact of each independent variable with a statistical significance threshold of $\alpha=0.05$. The results of this analysis are reported in Table IV. Follow-up analyses were performed using unequal variances t-tests (Table V). All analyses were performed using R statistical language software (version 3.3.1) $(16,17)$.

\section{Results}

Descriptive statistics of patients. A total of 48 patients were enrolled and analyzed in the current study, including $71 \%$ males and $29 \%$ females. The age descriptive statistics are reported in Table II. When considering the stage of the disease and the subregion, 16 patients were determined to have stage III disease and 32 patients had stage IV disease. Overall, $46 \%$ of the cases involved the tonsil region, $40 \%$ involved the base of the tongue and $14 \%$ involved both of the subregions. The immunohistochemical data indicated the presence of HPV in $40 \%$ of the patients.

Table III reports the descriptive statistics of the $15 \mathrm{QoL}$ C30 scales and of the $18 \mathrm{H} \& \mathrm{~N} 35$ scales. The functioning scale with the lowest average score was global QoL $(15,16)$, whereas the functioning scale with the highest score was on the cognitive functions scale. The symptom with the highest average self-reported score in the QLQ-C30 survey was C30-SL (insomnia) $(14,16)$, followed by C30-FI (financial difficulties) and by C30-CO (constipation) $(14,16)$. In the H\&N35 questionnaire, the symptoms with the highest self-reported scores were dry mouth, sticky saliva and use of painkillers $(15,16)$.

Variables associated with HR-QoL. Table IV reports the results of MANOVAs predicting the QLQ-C30 and the H\&N35 scale scores. In the prediction of the QLQ-C30 scales, only one independent variable, the age of the patient at the time of the diagnosis, showed a significant effect, whereas no variables significantly predicted the H\&N35 scales. The effect of age was followed-up with several t-tests, reported in Table V. Patients who were older than 60 at the time of the diagnosis tended to report worse physical functioning, worse 
Table III. Results of EORTC QLQ C30 and H\&N35.

\begin{tabular}{|c|c|c|c|c|}
\hline Scale & Average & Standard deviation & Median & Range \\
\hline \multicolumn{5}{|l|}{ QLQ-C30 } \\
\hline Global Quality of Life & 70.7 & 26.7 & 75 & $0-100$ \\
\hline Physical functioning & 82.4 & 18.1 & 86.7 & $33.3-100$ \\
\hline Role functioning & 85.8 & 23.3 & 100 & 0-100 \\
\hline Emotional functioning & 80.9 & 21.6 & 91.7 & $16.6-100$ \\
\hline Cognitive functioning & 89.2 & 19 & 100 & $16.6-100$ \\
\hline Social functioning & 82.3 & 26.3 & 100 & 0-100 \\
\hline Fatigue & 17.8 & 18.6 & 11.1 & $0-66.7$ \\
\hline Nausea and vomiting & 1 & 5.3 & 0 & $0-33.3$ \\
\hline Pain & 14.2 & 23.1 & 0 & $0-83.3$ \\
\hline Dyspnea & 10.4 & 23 & 0 & $0-100$ \\
\hline Insomnia & 20.1 & 26.4 & 0 & $0-100$ \\
\hline Appetite loss & 9 & 21.5 & 0 & $0-100$ \\
\hline Constipation & 18.8 & 26.5 & 0 & $0-100$ \\
\hline Diarrhea & 0.7 & 4.8 & 0 & $0-33.3$ \\
\hline Financial difficulties & 19.4 & 30.6 & 0 & $0-100$ \\
\hline \multicolumn{5}{|l|}{ QLQ-N\&H35 } \\
\hline Pain & 6.4 & 11.8 & 0 & $0-58.3$ \\
\hline Swallowing & 16.6 & 17.8 & 12.5 & $0-66.7$ \\
\hline Sensing problems & 18.4 & 23.6 & 16.7 & $0-100$ \\
\hline Speech problems & 14.6 & 17.6 & 11.1 & $0-77.8$ \\
\hline Trouble with social eating & 12.2 & 17.9 & 8.3 & $0-75$ \\
\hline Trouble with social contact & 9.6 & 17.2 & 0 & $0-73.3$ \\
\hline Sexual life & 26.7 & 36.2 & 0 & $0-100$ \\
\hline Teeth & 31.3 & 33.3 & 33.3 & $0-100$ \\
\hline Opening mouth & 12.5 & 26.3 & 0 & $0-100$ \\
\hline Dry mouth & 41 & 39.6 & 33.3 & $0-100$ \\
\hline Sticky saliva & 31.9 & 38.3 & 16.7 & $0-100$ \\
\hline Coughing & 17.4 & 26.6 & 0 & $0-100$ \\
\hline Feeling ill & 4.1 & 14.78 & 0 & $0-66.7$ \\
\hline Use of pain killers & 31.3 & 46.8 & 0 & $0-100$ \\
\hline Nutritional supplement use & 22.9 & 42.4 & 0 & $0-100$ \\
\hline Feeding tube & 2.1 & 14.4 & 0 & $0-100$ \\
\hline Weight loss & 14.6 & 35.7 & 0 & $0-100$ \\
\hline Weight gain & 25 & 43.8 & 0 & $0-100$ \\
\hline
\end{tabular}

EORTC, European Organization for the Research and Treatment of Cancer; QLQ C30, quality of life questionnaire-core 30; H\&N35, specific questionnaire for the head and neck area.

role functioning, more constipation, and more appetite loss compared to patients that were $<60$ years at the time of diagnosis.

\section{Discussion}

There are several reasons to change treatment strategies in patients affected by HPV-induced OSCC, as the international guidelines on the treatment of HPV-associated oropharyngeal squamous cell carcinoma are currently the same as for non-HPV-associated OSCC. The patients are treated with surgery or RT in the early-stages, and with combined treatment in the advanced-stages (4). It currently appears that the success of the various approaches is similar, and that the treatment selection must be made with consideration of associated therapeutic morbidities and the long-term QoL $(25,26)$.

In the past few decades RT techniques have changed. Functional outcomes between Intensity Modulated Radio Therapy (IMRT) and standard 2D RT are controversial in the literature; however, it is unanimous on the best functional results on chewing functioning, swallowing difficulty, taste and xerostomia may be better or identical compared with standard 2D RT $(27,28)$. The anatomical structures spared by IMRT improve 
Table IV. GLM-MANOVA test of the effects of the clinical and demographic variables on EORTC QLQ-C30 and H\&N35 scales.

A, Dependent variables: QLQ-C30 scales

\begin{tabular}{lcccccc}
\hline Variable & Wilk's $\lambda$ & F & Num df & Den df & P-value & Sample size (n) \\
\hline HPV & 0.662 & 1.09 & 15 & 32.0 & 0.402 & 48 \\
Treatment & 0.240 & 1.19 & 45 & 86.9 & 0.239 & 47 \\
Stage & 0.897 & 0.25 & 15 & 32.0 & 0.997 & 0.605 \\
Sex & 0.711 & 0.87 & 15 & 32.0 & 0.007 & 48 \\
Age group & 0.429 & 2.84 & 15 & 32.0 & 48 \\
\hline
\end{tabular}

B, Dependent variables: QLQ-H\&N35 scales

\begin{tabular}{lcccccc}
\hline HPV & 0.737 & 0.57 & 18 & 29.0 & 0.889 & 48 \\
Treatment & 0.275 & 0.79 & 54 & 78.3 & 0.824 & 47 \\
Stage & 0.744 & 0.55 & 18 & 29 & 0.904 & 48 \\
Gender & 0.605 & 1.05 & 18 & 29 & 0.438 & 48 \\
Age group & 0.672 & 0.79 & 18 & 29 & 0.698 & 48 \\
\hline
\end{tabular}

Reported models are unifactorial (i.e., a separate MANOVA was performed for each independent variable). All the analyses were performed on 48 patients, with the exception of those in which the independent variable was treatment, which were performed on 47 patients. MANOVA, multivariate analysis of variance; EORTC, European Organization for the Research and Treatment of Cancer; QLQ-C30, quality of life questionnaire-core 30; H\&N35, specific questionnaire for the head and neck area; HPV, human papilloma virus; df, degrees of freedom.

Table V. Follow-up t-tests to evaluate the effect of age on QLQ-C30 scales.

\begin{tabular}{|c|c|c|c|c|c|}
\hline QoL-C30 scale & Average $<60$ years & Average $\geq 60$ years & $\mathrm{t}$ & df & P-value \\
\hline Overall quality of life & 72.9 & 68.4 & 0.582 & 45.657 & 0.564 \\
\hline Physical functioning & 89.2 & 75.6 & 2.793 & 40.939 & 0.008 \\
\hline Role functioning & 93.1 & 78.5 & 2.259 & 33.301 & 0.031 \\
\hline Emotional functioning & 76.7 & 85.1 & -1.348 & 43.555 & 0.185 \\
\hline Cognitive functioning & 92.4 & 86.1 & 1.144 & 45.995 & 0.258 \\
\hline Social functioning & 79.9 & 84.7 & -0.637 & 44.086 & 0.528 \\
\hline Fatigue & 16.2 & 19.4 & -0.600 & 45.191 & 0.552 \\
\hline Nausea or vomiting & 0 & 2.1 & -1.366 & 23.000 & 0.185 \\
\hline Pain & 11.1 & 17.4 & -0.938 & 45.814 & 0.353 \\
\hline Dyspnea & 6.9 & 13.9 & -1.049 & 32.731 & 0.302 \\
\hline Insomnia & 20.8 & 19.4 & 0.180 & 44.288 & 0.858 \\
\hline Appetite loss & 15.3 & 2.8 & 2.089 & 28.216 & 0.046 \\
\hline Constipation & 8.3 & 29.2 & -2.930 & 37.311 & 0.006 \\
\hline Diarrhea & 0 & 1.4 & -1.000 & 23.000 & 0.328 \\
\hline Financial difficulties & 20.8 & 18.1 & 0.311 & 42.323 & 0.757 \\
\hline
\end{tabular}

The analyses were performed on 48 participants. QLQ C30, quality of life questionnaire-core 30 (24); t, t-statistic of the unequal variance t-test; df, degrees of freedom.

long-term effects with regard to swallowing, maintaining a local control of the disease. For these reasons, IMRT may be considered as a potential standard treatment for oropharyngeal carcinoma (28-31). Similarly, in patients treated with surgery in the early-stages, a long-term functional improvement may be observed, comparable with patients who received adjuvant RT following surgery of a primary tumor $(31,32)$.
Some scholars suggest that patients not treated with surgery have more problems concerning xerostomia, dental problems and taste, as compared with patients treated with isolated surgery or followed with adjuvant RT $(27,32)$. When comparing the results of the QoL questionnaire completed by patients exclusively treated with surgery with those of patients who received any type of RT treatment, the latter 
complained significantly of xerostomia and dental problems $(29,32,33)$.

In the present study, 14 cases were treated with surgery followed by adjuvant RT; 13 cases were treated with surgery followed by CTRT; 10 cases were treated with sole CTRT and 10 cases were treated exclusively with surgery. According to the statistical analysis conducted in the present study, which omitted the single case of the patient who was treated exclusively with RT, the differences in general QoL and of the single scales that were analyzed are not correlated with the type of therapy selected for the treatment of the patient.

In the last three decades, pathological models of head and neck squamous carcinomas have changed. In particular, the incidence of HPV-associated tumors has increased, as compared with tumors associated with alcohol and tobacco consumption $(1,33,34)$. It is well known that patients with high-risk HPV-associated oropharyngeal cancer have increased survival rates, suggesting a high response to RT (13). Immunohistochemical analysis of the results indicated that the presence of HPV in $40 \%$ of the patients involved in the present study was consistent with the data from the Memorial Sloan Kettering Cancer Center (MSKCC), where in 2000 in the USA are described $40 \%$ of HPV-induced oropharyngeal squamous cell carcinomas. While, the same study demonstrated an incidence increase of $60-70 \%$ in the United States of HPV-associated OSCC between 2010 and 2014 (1). The study of QoL, conducted by a group from the Fred Hutchinson Cancer Research Centre of Seattle and Washington, using questionnaires from Washington University, demonstrated how patients with high-risk HPV in the pre-treatment phase experience an improved QoL, as compared with patients with low-risk HPV or HPV-negative cases (32). Conversely, immediately following the surgery, the same patients with high-risk HPV reported a more significant decrease in QoL, as compared with patients with low-risk HPV and with patients who were HPV-negative. One year following the treatment, there were no significant differences in QoL observed among the patients, when considering the stage of HPV (32). These results suggest that a decrease in QoL immediately following surgery in patients with high-risk HPV may be due to the high intensity of the treatment administered in this population $(32,35)$. Deintensification of the treatment was suggested for patients with HPV-HR oropharyngeal squamous carcinoma, as they are typically younger and have an improved survival rate, compared with other patients with the same disease (26). The importance of determining the stage of HPV in patients with oropharyngeal carcinoma may lead to a deintensified therapeutic regiment for the patient, in order to optimize survival and QoL trajectories in this population (26).

Currently, standard treatments are also applicable in patients who are HPV-positive where robotic transoral surgery has revealed the greatest prognosis and functional results, even though the most effective therapy for HPV-associated carcinoma is still under discussion, and trans oral robotic surgery (TORS) or surgery associated with RT is able to provide a good level of QoL (25). With a combination of TORS and adjuvant therapy, the disease may be controlled both in HPV-positive and HPV-negative tumors. In particular, the benefits of this type of surgery appear to include good survival rates, allowing the reduction of the dose and volume of the following RT, in order to reduce long-term toxicity; this characterizes combined radical CTRT treatment. $(25,26,36)$.

A number of studies aimed at evaluating the possible deintensification of current treatments able to be applied to the low-medium risk category of patients are in progress. Such deintensification may consist of a reduction of the radiation dose and/or alterations of the concomitant therapy; for example, avoiding chemotherapy and replacing it with a biological therapy, such as cetuximab, and introducing neoadjuvant chemotherapy in order to avoid concomitant chemotherapy. At this time, there is insufficient data to modify the selection of the therapy depending on the risk profile $(25,31,37,38)$.

Furthermore, it is necessary to reflect upon two further aspects: The type of laboratory tests conducted in order to evaluate the presence of HPV in patients, and the type of questionnaire provided to determine QoL.

Increasing evidence concerning the diagnostic role of HPV HR in oropharyngeal oncology, which is associated with a more favourable prognosis and a higher radiosensibility, suggests that it is required to identify useful molecular markers, which may be integrated into the clinical management of oropharyngeal SCC (39). The use of p16 in immunohistochemistry, as a marker to determine the presence of HPV, is controversial. For certain authors, it may be associated with a high rate of false-positive results, increasing the necessity for the identification of novel markers for the infection of oral HPV $(3,9)$; these studies suggest not relying exclusively on p16 for HPV screening $(3,35)$. The inconsistency of the methods currently used to identify molecular markers in the field of head and neck oncology, in particular for HPV infection, is one of the primary obstacles faced in clinical practice. For this reason, an agreement on the methods used to identify high-risk HPV in squamous cell carcinoma in head and neck oncology is essential $(3,9,19,21,39)$.

Statistical analysis carried out on the patients involved in the current study, considering HPV-positivity to be an independent variable, indicated that it has no significant influence on the final QoL score, as compared with HPV-negative patients. These results appear to be concordant with those of the Seattle team study, which stated that one year following therapy the patient QoL was not statistically different between patients who were HPV-negative and HPV-positive (35). In the present study, the results on QoL correlated with HPV is justified as the patient sample considered had a long-term survival time $\geq 5$ years; there are patients with survival times between 5-16 years (mean, 9.5 years) following treatment.

The EORTC questionnaire used $(14,15)$, as compared with the one proposed by Washington University, is more detailed in addressing the various aspects of activity, the body and social functions, allowing for a more specific evaluation, particularly with regards to swallowing and aspects of global health. The EORTC questionnaire is widely used due to its reliability and effectiveness $(14,15)$. Currently, there is no questionnaire available for this particular field that may be universally adopted for the improved analysis of variables, and also to interpret results with the same parameters.

In conclusion, completing the exposition of the data collected in the present study, it was determined that QoL is influenced by age in patients with a long-term survival time 
who were treated for oropharyngeal carcinoma at the base of tongue or in the tonsils. Scrutinizing the age variable with several t-tests, it emerged that patients who were older than $\geq 60$ at the time of the diagnosis tended to report poorer physical functioning (questions 1-5 of the QLQ-C30 questionnaire), more severe limits to physical ability (questions 6 and 7 of QLQ-C30), more appetite loss (question 13 of QLQ-C30) and more constipation (question 16 QLQ-C30), as compared with younger patients. Since analyzed cases are taken in consideration from 5-16 years following treatment, and 69-years-old is the average age of patients in the present study, the results may be influenced by aging.

In conclusion, the available data supports the concept that oropharyngeal tumors have been increasing in incidence globally over the last 20 years, as compared with other types of head and neck-associated tumors, particularly in Western countries (1). With respect to the treatment of the disease and based on current understanding, HPV-positive oropharyngeal cancer may be considered a singular type of cancer in head and neck area with relatively favourable outcomes. Patients with HPV-positive oropharyngeal cancer are generally younger and in better health (less comorbidity). The presence of HPV type 16 may also be considered a prognostic marker for a higher rate of global survival with total recovery, but its predictive role has not yet been demonstrated $(38,39)$. Numerous questions regarding the natural history of HPV infections are still under discussion. The ineffectiveness of shared methods for identifying molecular markers for HPV infection is one of the primary obstacles to their use in clinical practice. For this reason, a consensus on the methods to be used for identifying high-risk HPV in squamous cell carcinoma in the head and neck area is required.

In the present study, QoL, taking into account the presence of HPV, the type of treatment, the subregion of the tonsils vs. the base of the tongue and the disease stage at the time of diagnosis, was revealed to not be influenced by the aforementioned variables. The data are consistent with previous studies, where the role of HPV HR OSCC and QoL in general, one year following treatment, was not able to be significantly distinguished from the HPV-negative role. The tissue samples analyzed in the current study, including pathology at an advanced-stage and with associated long-term patient survival, considered patients from 5-16 years following their treatment. Therefore, the results and the time gap indicate that the only significant variable affecting the QoL is the age of the patient.

The results of the present study determined that the long-term QoL of patients with HPV-associated advanced-stage oropharyngeal squamous cell cancer is as equally compromised as non-HPV-associated oropharyngeal squamous cell cancer. It is understood that patients with HPV-associated oropharyngeal cancer have a longer life expectancy and, therefore, may live longer but also experience the toxic effects of the treatment for longer (34). Therefore, developing and implementing a deintensified form of treatment for HPV-associated oropharyngeal cancer is justified.

Future studies may consider a further expansion of the sample size, a consensus on the methods used to identify HPV and comparisons with the results of various other studies. Further studies are required in order to investigate the use of deintensified treatments that do not compromise results, but are able to reduce the risk of adverse effects and the deterioration of QoL.

\section{References}

1. Shah JP, Patel SG, Singh B: Jatin Shah's Head and Neck Surgery and Oncology. 4th Edition. Elsevier, Philadelphia, PA, 2012.

2. Ragin CC and Taioli E: Survival of squamous cell carcinoma of the head and neck in relation to human papillomavirus infection: Review and meta-analysis. Int J Cancer 121: 1813-1820, 2007.

3. Bussu F, Sali M, Gallus R, Petrone G, Zannoni GF, Autorino R, Dinapoli N, Santangelo R, Vellone VG, Graziani C, et al: Human Papillomavirus (HPV) infection in squamous cell carcinomas arising from the oropharynx: Detection of HPV DNA and p16 immunohistochemistry as diagnostic and prognostic indicators-a pilot study. Int J Radiation Oncol Biol Phys 89: 1115-1120, 2014.

4. NCCN Clinical Practice Guidelines in Oncology (NCCN Guidelines). Head and Neck Cancers. Version 1.2015. National Comprehensive Cancer Network, Inc., 2015.

5. Boscolo-Rizzo P, Tirelli G, Mantovani M, Baggio V, Lupato V, Spinato G, Gava A and Da Mosto MC: Non-endemic locoregionally advanced nasopharyngeal carcinoma: Long-term outcome after induction plus concurrent chemoradiotherapy in everyday clinical practice. Eur Arch Otorhinolaryngol 272: 3491-3498, 2015.

6. Pourel N, Peiffert D, Lartigau E, Desandes E, Luporsi E and Conroy T: Quality of life in long-term survivors of oropharynx carcinoma. Int J Radiat Oncol Biol Phys 54: 742-51, 2002.

7. Ausoni S, Boscolo-Rizzo P, Singh B, Da Mosto MC, Spinato G, Tirelli G, Spinato R and Azzarello G: Targeting cellular and molecular drivers of head and neck squamous cell carcinoma: Current options and emerging perspectives. Cancer Metastasis Rev 35: 413-426, 2016.

8. Boscolo Rizzo P, Rampazzo E, Perisinotto E, Piano MA, Giungo S, Baboci L, Spinato G, Spinato R, Tirelli G, Da Mosto MC, et al: Telomere shortening in mucosa surrounding the tumor: Biosensor of field cancerization and prognostic marker of mucosal failure in head and neck squamous cell carcinoma. Oral Oncol 51: 500-507, 2015.

9. Elrefaey S, Massaro MA, Chiocca S, Chiesa F and Ansarin M: HPV in oropharyngeal cancer: The basics to know in clinical practice. Acta Otorhinolaryngol Ital 34: 299-309, 2014.

10. Funk GF, Karnell LH and Christensen AJ: Long term health-related quality of life in survivors of head and neck cancer. Arch Otolaryngol Head Neck Surg 138: 123-133, 2012.

11. Serra A, Caltabiano R, Scalia G, Palmucci S, Di Mauro P and Cocuzza S: Papillary squamous cell carcinoma of the palatine tonsil: A rare cancer of the head and neck. Acta Otorhinolaryngologica Italica 37: 1-5, 2017.

12. Maxwell JH, Mehta V, Wang H, Cunningham D, Duvvuri U, Kim S, Johnson JT and Ferris RL: Quality of life in head and neck cancer patients: Impact of HPV and primary treatment modality. Laryngoscope 124: 1592-1597, 2014.

13. Wan Leung S, Lee TF, Chien CY, Chao PJ, Tsai WL and Fang FM: Health related Quality of life in 640 head and neck cancer survivors after radiotherapy using EORTC QLQ-C30 and QOL-H\&N35 questionnaires. BMC Cancer 11: 128, 2011.

14. QoLQuestionnaire-Core 30 (QLQ-C30), EORTC-ITA.http://groups. eortc.be/qol/why-do-we-need-modules. Accessed March 3, 2015.

15. QoL Questionnaire-Head and Neck 35 (QLQ-H\&N35), EORTC-ITA. http://groups.eortc.be/qol/why-do-we-needmodules. Accessed March 3, 2015.

16. Fayers PM, Aaronson NK, Bjordal K, Groenvold M, Curran D and Bottomley A; On behalf of the EORTC Quality of Life Group: The EORTC QLQ-C30 Scoring Manual. 3rd Edition. European Organization for Research and Treatment of Cancer, Brussels, 2001.

17. Aaronson NK, Ahmedzai S, Bergman B, Bullinger $M$, Cull A, Duez NJ, Filiberti A, Flechtner H, Fleishman SB, de Haes JC, et al: The European Organization for research and treatment of cancer QLQ-C30: A quality-of-life instrument for use in international clinical trials in oncology. J Natl Cancer Inst 85: 365-376, 1993.

18. Baboci L, Holzinger D, Boscolo Rizzo P, Tirelli G, Spinato R, Lupato V, Fuson R, Schmitt M, Michel A, Halec G, et al: Low prevalence of HPV-driven head and neck squamous cell carcinoma in North-East Italy. Papillomavirus Research 2: 133-140, 2016. 
19. Schmitt M, Dondog B, Waterboer T and Pawlita M: Homogeneous amplification of genital human alpha papillomaviruses by PCR using novel broad-spectrum GP5+ and GP6+ primers. J Clin Microbiol 46: 1050-1059, 2008.

20. Del Mistro A, Bonaldi L, Bertorelle R, Minucci D, Franzetti M, Cattelan A, Bonoldi E, Sposetti R, Torrisi A and Chieco Bianchi L: Genital human papillomavirus types in immunocompetent and immunodepressed women in northeast Italy: Prevalence and cytomorphological correlations. J Low Genit Tract Dis 5: 12-20, 2001.

21. Carson F and Hladik C: Histotechnology: A Self Instructional Text. 3rd edition. American Society for Clinical Pathology Press, Hong Kong, 2009.

22. Roche PC and Hsi ED: Immunohistochemistry-Principles and Advances. In: Manual of Clinical Laboratory Immunology. Rose NR (ed). 6th edition. ASM Press, Washington DC, 2002.

23. Field A, Miles J and Field Z: Discovering Statistics Using R. SAGE Publications, London, 2012.

24. Ruxton GD: The unequal variance t-test is an underused alternative to Student's t-test and the Mann-Whitney U test. Behav Ecol 17: 688-690, 2006.

25. Hinni ML and Lott DG (eds): Contemporary Transoral Surgery for Primary Head and Neck Cancer. Plural Publishing, San Diego, CA, 2014

26. O'Sullivan B, Huang SH, Siu LL, Waldron J, Zhao H, Perez-Ordonez B, Weinreb I, Kim J, Ringash J, Bayley A, et al: Deintensification candidate subgroups in human papillomavirus-related oropharyngeal cancer according to minimal risk of distant metastasis. J Clin Oncol 31: 543-550, 2013.

27. Mendenhall WM, Amdur RJ, Morris CG, Kirwan JM and Li JG: Intensity-modulated radiotherapy for oropharyngeal squamous cell carcinoma. Laryngoscope 120: 2218-2222, 2010.

28. Eisbruch A, Harris J, Garden AS, Chao CK, Straube W, Harari PM, Sanguineti G, Jones CU, Bosch WR and Ang KK Multi-institutional trial of accelerated hypofractionated intensity-modulated radiation therapy for early-stage oropharyngeal cancer (RTOG 00-22). Int J Radiat Oncol Biol Phys 76 $1333-1338,2010$

29. Yong JH, Beca J, O'Sullivan B, Huang SH, McGowan T, Warde P and Hoch JS: Cost-effectiveness of intensity-modulated radiotherapy in oropharyngeal cancer. Clin Oncol (R Coll Radiol) 24: $532-538,2012$.

30. Kurzweg T, Möckelmann N, Laban S and Knecht R: Current treatment options for recurrent or metastatic head neck cancer: A post-ASCO 2011 update and review of last year's literature. Eur Arch Otorhinolaryngol 269: 2157-2167, 2012.
31. Hitt R, Irigoyen A, Cortes-Funes H, Grau JJ and García-Sáenz JA, Cruz-Hernandez JJ; Spanish Head and Neck Cancer Cooperative Group (TTCC): Phase II study of the combination of cetuximab and weekly paclitaxel in the first-line treatment of patients with recurrent and/or metastatic squamous cell carcinoma of head and neck. Ann Oncol 23: 1016-1022, 2012.

32. Shi W, Kato H, Perez-Ordonez B, Pintilie M, Huang S, Hui A, O'Sullivan B, Waldron J, Cummings B, Kim J, et al: Comparative prognostic value of HPV16 E6 mRNA compared with in situ hybridization for human oropharyngeal squamous carcinoma. J Clin Oncol 27: 6213-6221, 2009.

33. Baboci L, Boscolo-Rizzo P, Holzinger D, Bertorelle R, Biasini L, Michel A, Schmitt M, Spinato G, Bussani R, Alemany L, et al: Evidence of the causal role of human papillomavirus type 58 in an oropharyngeal carcinoma. Virol J 10: 334, 2013.

34. D'Souza G and Dempsey A: The role of HPV in head and neck cancer and review of the HPV vaccine. Prev Med 53 (Suppl 1): S5-S11, 2011

35. Fallai C, Perrone F, Licitra L, Pilotti S, Locati L, Bossi P, Orlandi E, Palazzi M and Olmi P: Oropharyngeal squamous cell carcinoma treated with radiotherapy or radiochemotherapy: Prognostic role of TP53 and HPV status. Int J Radiat Oncol Biol Phys 75: 1053-1059, 2009 .

36. Franchin G, Minatel E, Gobitti C, Talamini R, Vaccher E, Sartor G, Politi D, Trovò MG and Barzan L: Radiotherapy for patients with early-stage glottic carcinoma: Univariate and multivariate analyses in a group of consecutive, unselected patients. Cancer 98: 765-772, 2003

37. Da Mosto MC, Lupato V, Romeo S, Spinato G, Addonisio G, Baggio V, Gava A and Boscolo-Rizzo P: Is neck dissection necessary after induction plus concurrent chemoradiotherapy in complete responder head and neck cancer patients with pretherapy advanced nodal disease? Ann Surg Oncol 20: 250-256, 2013.

38. Pignon JP, Bourhis J, Domenge C and Designé L: Chemotherapy added to locoregional treatment for head and neck squamous-cell carcinoma: Three meta-analyses of updated individual data. MACH-NC Collaborative Group. Meta-Analysis of Chemotherapy on Head and Neck Cancer. Lancet 355: 949-955, 2000.

39. Sharma A, Méndez E, Yueh B, Lohavanichbutr P, Houck J, Doody DR, Futran ND, Upton MP, Schwartz SM and Chen C: Human papillomavirus-positive oral cavity and oropharyngeal cancer patients do not have better quality-of-life trajectories. Otolaryngol Head Neck Surg 146: 739-745, 2012. 